\title{
Structural Assessment of the Roman Wall and Vaults of the Cloister of Tarragona Cathedral
}

\begin{abstract}
The Mediterranean city of Tarragona was a capital city in Roman times. Nowadays, the remains of the ancient constructions coexist with many subsequent buildings. This is the case of the Gothic Cathedral cloister, whose walls partially take advantage of the remains of the temenos's wall. This paper focuses on the assessment of that unique overlapping of construction phases. The investigation is performed through an unprecedented topographical survey by means of massive data capture techniques. This information is the basis for the mechanical assessment of the equilibrium conditions of the northern corner of the gallery, which is performed on the well-known theoretical framework of limit analysis by means of thrust lines. The study allowed to enhance the understanding about the equilibrium conditions and the deformation processes of the gallery masonry elements, where the mechanical relation between the Roman and Gothic walls is essential.
\end{abstract}

Keywords 3D model, Structural assessment, Graphic documentation techniques

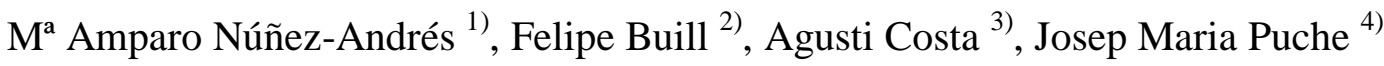

1) Department of Geotechnical Engineering and Geo-Sciences (ETCG). Universitat Politècnica de Catalunya.m.amparo.nunez@upc.edu

2) Department of Geotechnical Engineering and Geo-Sciences (ETCG). Universitat Politècnica de Catalunya.felipe.buil@upc.edu

3) Universitat Rovira i Virgili. ETSA Reus, Campus Bellissens. agusti.costa@urv.cat

4) ICAC, Institut Català d'Arqueologia Clàssica jpuche@icac.cat

\section{Introduction}

The city of Tarragona is located at the Mediterranean coast of Catalunya (Spain). Known as Tarraco, it was a capital city in Roman times and until eighth century. The city lived a second period of splendour which began at the end of eleventh century. Then the construction of the Gothic Cathedral started at the location of the temenos, where it was built the temple dedicated to Emperor Augustus.

Medieval builders took advantage of the existence of the remains of Roman times, and adapted their project to the location. Thus, both Roman and Gothic structures coexisted, defining a structural continuum with mechanical interaction. It is one of several singularities of the Cathedral enclosure, and its current management and preservation are a challenge of the present times.

The Roman wall of the temenos was $0.90 \mathrm{~m}$ thick and $12 \mathrm{~m}$ high, and its structural role was limited to supporting the porch and its own weight. Subsequently, a medieval vaulted gallery was added, together with a building known as the 'Casa dels Canonges' (Canons' House). At the same time, when the construction of the perimeter gallery of the cloister was planned, it took into account the existence of the Roman wall, which worked as a lateral reinforcement to support the thrusts of the vaults. 
This situation raises several questions: How did the additions in later periods alter the Roman wall? What is the mechanical behaviour of the cloister's gallery?, Are the observed geometric deviations relevant?, Could the gallery collapse, either totally or partially? There is also a desire and need to deepen knowledge of a structure that is over 2000 years old.

Heritage documentation techniques are currently very varied, and international conservation and restoration specialists recommend undertaking surveys accurately and rigorously [1] [2] [3]. The use of massive data capture techniques (MDC), such as terrestrial laser scanning and digital photogrammetry, enable to obtain highly accurate topographic bases in a short period of time. This is particularly relevant in the assessment of historic buildings, as it is difficult to perform surveys with other techniques.

Numerous investigations have addressed during the last years the assessment of masonry constructions using these techniques. Beyond the most obvious applications for surveying and modelling complex structures [4] [5], it is possible to study in depth the displacements suffered by the masonry [6] [7] [8]. In addition, these 3D surveys can be the base to perform structural analysis using techniques such as finite elements [9], or limit analysis by means of thrust lines. The theory is well developed nowadays, and is a sound procedure for assessing the stability of masonry structures [10] [11] [12] [13]. These techniques have been used for masonry buildings [14] [15] [16] and other arched structures, such as masonry bridges [17] [18] [19].

The paper deals with the geometric survey and the mechanical assessment of this unique overlapping of construction phases, where Roman and Medieval masonry works together. The study is focused on the northern corner of the cloister, and the new topographical documentation of the cloister is unprecedented, as well as the structural analysis of equilibrium conditions. Most studies about this location are focused on artistic or historical matters [20]. Present investigation goes one-step beyond common references about the cloister of Tarragona, focusing on the masonry construction stability.

\subsection{Brief historical background of Tarraco.}

A cathedral is a key element in many cities as it is often the community's main religious building and has a place in a city's history. In Tarragona, this symbolic role is enhanced by the topographical situation of the cathedral and the historical relevance of the city. Consequently, Tarragona Cathedral is a singular masterpiece. It has a great scenographic effect since it is located in the highest part of the city, and defines the skyline. It could be said that it is the city of Tarragona's reason for being and existing [21].

The diocese of Tarragona can be considered one of the oldest documented. There is evidence of the life and martyrdom of Saint Fructuous, who was bishop in 249 BCE and was considered the first saint of the Iberian Peninsula. Tarraco was a capital city in Roman times. It was quickly transformed into an ecclesiastical metropolis that was one of the important religious capital cities of the Peninsula. This position was lost after the Islamic invasion of $711 \mathrm{BCE}$, especially when the bishop Saint Prosper fled to Italy [22].

In 1089, Pope Urban II gave the mitre of Tarragona to the bishop of Vic, Seniofred de Lluçà, and encouraged the Count of Barcelona to reconquer the city, which was still under Islamic control. Count Ramón Berenguer III wanted to recover the ecclesiastical metropolis of Tarragona to gain independence from Carcassonne and break with the political dependence on the French Crown. He 
recovered the city and the bishopric in 1091. Then, the construction of the current Cathedral began [23] [24].

It could be said that the city was reborn due to the will of the Pope and the need to recover the diocese of Tarragona. This led to the construction of the cathedral, around which the new city was built. The new medieval city occupied the site of the ancient Roman Tarraco and used its visible remains. This is especially true in the case of the Cathedral, since it is placed in exactly the same location as the Temple of Augustus, as ascertained in recent archaeological works [25] (Figure 1).

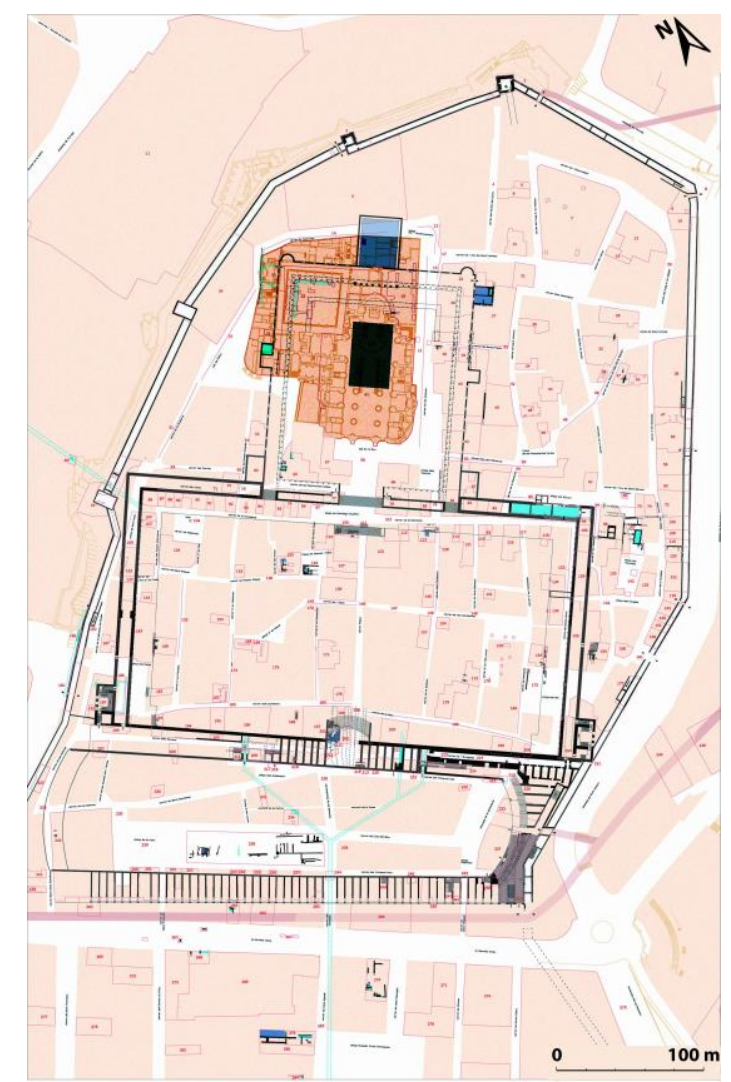

Fig. 1 Roman remains of the CPHC (Concilium Provinciae Hispaniae Citerioris) and Cathedral enclosure over the urban layout of Tarragona [6].

Most of the Roman architectural structures from the area of worship dedicated to Emperor Augustus were still standing in the twelfth century. They included the temple, the temenos and the surrounding monumental portico, which is now known to have been $115 \mathrm{~m}$ in length, with an average height of 12 $\mathrm{m}$.

Its monumental character and state of preservation determined the planning of the medieval Cathedral enclosure. It affected the specific location of the temple and the anomalous position of the cloister [26] (Figure 1), which is located between the western transept and the apse, when its natural position would be at the feet of the eastern transept. This position was chosen due to the remains of the northwest corner of the enclosing wall of the temenos, which currently coincides exactly with the corner of the cloister.

\section{Methods and theoretical framework}

The study was based on two main procedures. First, topographical documentation provided relevant geometric information about the shape and deformations suffered by the gallery and the perimeter 
wall. Second, the structural assessment focused on the mechanical behaviour of the buttressing system and the equilibrium conditions of the masonry.

Metric information was obtained by geomatic procedures, and was then used to perform the structural analysis, based on the premise that the Roman wall was built with large stone blocks, on which other structures were built.

The masonry structure's equilibrium conditions were assessed using the theoretical framework of limit analysis, through the layout of thrust lines. It was established that the masonry has infinite compressive strength, no tensile strength, and sliding of the blocks is impossible. These assumptions are the basis of the lower bound theorem: if a combination of hypotheses can be found that result in a line of thrusts contained in the masonry, the structure will be stable and will not collapse. Furthermore, the position of the thrust line can be used to evaluate the safety of the structure.

The analysis of the equilibrium of the cloister's vaults was based on the premise that the structure was in good condition, since there was no severe pathology to indicate otherwise. Nevertheless, a certain loss of verticality was observed in some sections of the cloister's inner wall, which indicates that there was movement at some point. The cloister is a low-rise structure without large loads; the kind of structure that tends to be stable. In addition, the pointed shapes of the vaults and arches need less buttressing, since the horizontal thrust values tend to be lower.

Thus, the analytical procedure consisted of determining the thrust caused by the vaults and assessing the capacity of the buttresses to support this thrust. The closer the line of thrust to the limit of the section, the less safety margin the structure will have. This provides information about the equilibrium conditions governing the design of the structure.

\section{Documentation techniques}

Heritage documentation techniques are currently very varied, and international conservation and restoration specialists recommend undertaking surveys accurately and rigorously [1] [2] [3]. The graphic documentation of heritage can be performed in many ways: by sketching, through photographs in combination with measurements made with tape measures or hand-held laser distance measures, or rigorously by topographic and photogrammetric techniques. Due to their scope and rigour, the use of photogrammetric procedures has been prominent. In the last decade, photogrammetry has been used to supplement or replace terrestrial laser scanning thanks to significant advances like Structure-fromMotion (SfM). Usually, several of these techniques are used at the same time to supplement the documentation in the survey, but not all of them are valid procedures to obtain appropriate 3D model for a structural assessment.

In many cases, the possibility of computing in an accurate way is due to the availability of quality $3 \mathrm{~d}$ information. Furthermore, the runtime of the procedure must be taken into account, as well as the provided information, the financial cost of the work, and the accuracy (Table 1). Massive data capture techniques (terrestrial laser scanning and digital photogrammetry) allow fast results to be obtained in the field, and the entire process of exploitation of results is performed in the office.

Table 1. Measurement techniques characteristics.

\begin{tabular}{|ccccccc|}
\hline Technique & Model & $\begin{array}{c}\text { Time field / } \\
\text { office }\end{array}$ & Scale & Raw data & Cost & Accuracy \\
\hline Manual measuring & Little & $\begin{array}{c}\text { High / } \\
\text { Medium }\end{array}$ & Big & $\begin{array}{c}\text { Point } \\
\text { Vector }\end{array}$ & High & Medium \\
\hline
\end{tabular}




\begin{tabular}{|ccccccc|}
\hline $\begin{array}{c}\text { Photographs }+ \\
\text { measures }\end{array}$ & $\begin{array}{c}\text { Medium- } \\
\text { sized }\end{array}$ & $\begin{array}{c}\text { Medium / } \\
\text { Medium }\end{array}$ & Big & Surface & Low & Low \\
\hline Topography & All & $\begin{array}{c}\text { High / } \\
\text { Medium }\end{array}$ & All & $\begin{array}{c}\text { Point } \\
\text { Vector }\end{array}$ & $\begin{array}{c}\text { Medium } \\
\text { High }\end{array}$ & $\begin{array}{c}\text { High } \\
\text { Very High }\end{array}$ \\
\hline Laser Scanner & All & Low / High & All & Point & $\begin{array}{c}\text { High } \\
\text { Very High }\end{array}$ & $\begin{array}{c}\text { High } \\
\text { Very High }\end{array}$ \\
\hline $\begin{array}{c}\text { Digital } \\
\text { photogrammetry }\end{array}$ & All & Low / High & All & $\begin{array}{c}\text { Point } \\
\text { Vector }\end{array}$ & $\begin{array}{c}\text { High } \\
\text { Very High }\end{array}$ & $\begin{array}{c}\text { High } \\
\text { Very High }\end{array}$ \\
\hline Digitizer 3D & Little & $\begin{array}{c}\text { Low / } \\
\text { Medium }\end{array}$ & Big & Point & High & $\begin{array}{c}\text { High } \\
\text { Very High }\end{array}$ \\
\hline
\end{tabular}

Current surveying technologies play an important role in the process of increasing awareness of cultural heritage. They enable us to analyse and evaluate the geometry of monuments, and to discover their state of preservation and aesthetic properties [27].

From an analytical point of view, architectural heritage structures need to be calculated and assessed by mathematical models. To achieve this, we need to know the geometry in detail, as well as the displacements and damages suffered over time. Approximate or schematic geometries are not sufficient in many cases.

The metric information that is obtained can be used by many professionals who work in the fields of restoration and rehabilitation of monuments. One application is described in [28], where it is used to examine in detail the cracks, deformation, collapse and geometry of Alcántara Bridge and the Cathedral of Coria. Another interesting study is the use of terrestrial laser scanning (TLS) to determine differential movements of structures and progressive tilting, in order to evaluate the stability of cultural heritage structures [29].

Below, we describe the proposed laser scanning method for obtaining geometric information to assess the mechanical behaviour of a structure. The method is described and applied to a specific case study, the perimeter gallery of the cloister of Tarragona Cathedral, to highlight the potential of the proposed approach and confirm its suitability.

\section{Geomatic survey}

The three-dimensional survey of the perimeter gallery of the cloister and the Roman wall was carried out using massive data capture techniques such as terrestrial laser scanning and terrestrial digital photogrammetry. In both cases, a network of reference points needed to be established to georeference the model.

As a reference, we used the Institut Cartogràfic i Geològic de Catalunya's (ICGC) fourth order geodetic network of the area. Based on this resource, two traverses were designed to take the coordinates inside the Cathedral of both the cloister and the Roman wall (Figure 2). 


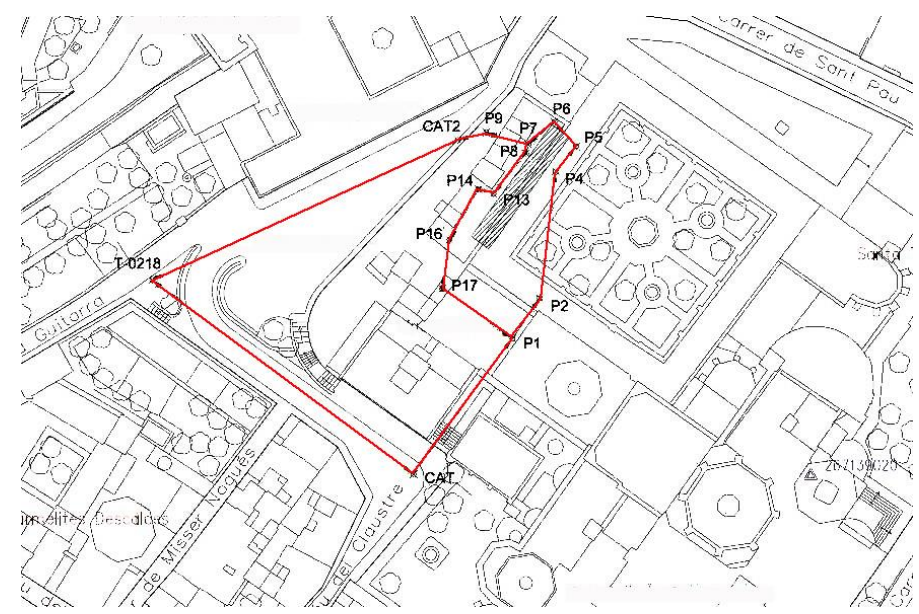

Fig. 2 Location of the points of the topographic traverses. The point call 'CAT' carry out the geodetic network of the ICGC, the 'Px' are the vertex established in the topographic survey

The main itinerary was a closed traverse, formed by 9 vertices, while the secondary itinerary was fitted inside this and formed by 6 vertices. Both itineraries were observed simultaneously, using the Moinot method.

The itineraries were adjusted by means of indirect observations of the least squares method for planimetry and altimetry. An extreme error of less than $2 \mathrm{~cm}$ was obtained, with a $95 \%$ level of reliability.

\subsection{Terrestrial laser scanner survey}

A time-of-flight laser device was used in the survey, a ScanStation C5 by Leica Geosystems. A high number of positions needed to be used to avoid occlusions, due to the characteristics of the area. A total of 15 scans were made, with a minimum work distance of $2 \mathrm{~m}$ and a maximum of $20 \mathrm{~m}$. A dense point cloud was obtained with a resolution of $1 \mathrm{~cm}$ (Figure 3).

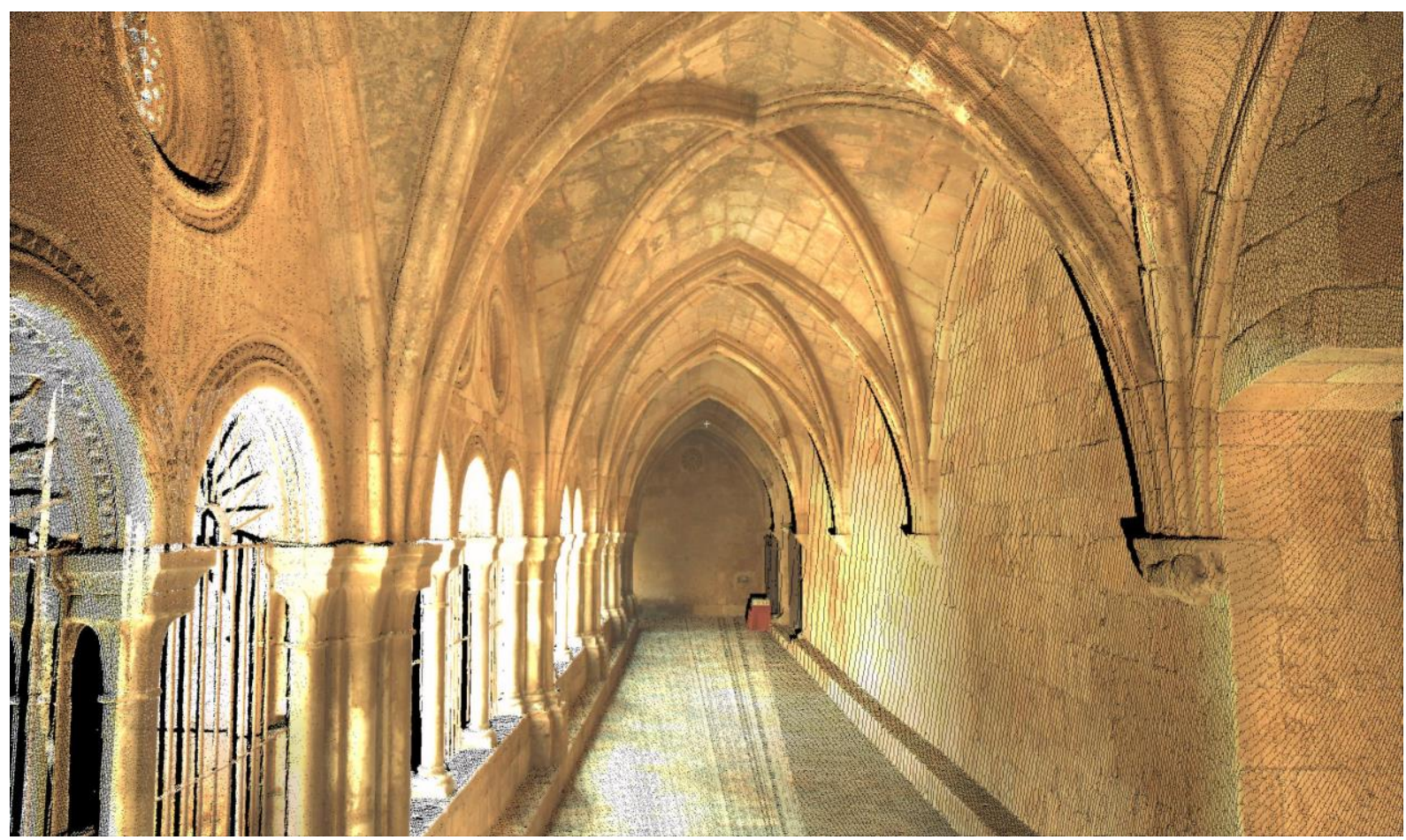

Fig. 3 Model of the points with colour of the perimeter gallery of the cloister. 
In addition, the internal camera of the scanner was used to photograph and assign colour to the point cloud. As a result, the cloud has associated intensity and colour information about the scanned object.

The coordinates of more than 191 million points were captured, of which 67.6 million belong to the Roman wall, and 65.5 million to the gallery.

The clouds were georeferenced by the indirect method. Coordinates were given to targets from topographic bases to locate the point clouds in the same reference system. Three of the scanned targets were discarded during the process because the error in the adjustment of the point cloud exceeded the established tolerance. This tolerance was established by error transmissions from the bases of the traverse, obtained after least square adjustment, and the estimation in a measured point with the instrumental and methodology used. Its magnitude was of $2.5 \mathrm{~cm}$. Finally, a continuous model with an estimated overall error of less than $2 \mathrm{~cm}$ was obtained in the registration of the point clouds.

Subsequently, this model was meshed using the program 3DReshaper. The mesh was obtained considering an average distance of $1 \mathrm{~cm}$ between points, the union of which generates a large number of linked triangles. The aim was to create a closed mesh, with the minimum number of holes and without modifying the external boundary. This mesh was then edited to correct wrong triangles and to fill the remaining gaps. The process was more complex for the gallery, due to the existence of the grille and a lot of holes.

\subsection{Photogrammetric survey}

Photogrammetric techniques were used to generate a 3D model of the window located in the centre of the Roman wall shown in Figure 4, and the capital of the column located near the gateway (Figure 5). The texture of both models was obtained from the photogrammetric survey.

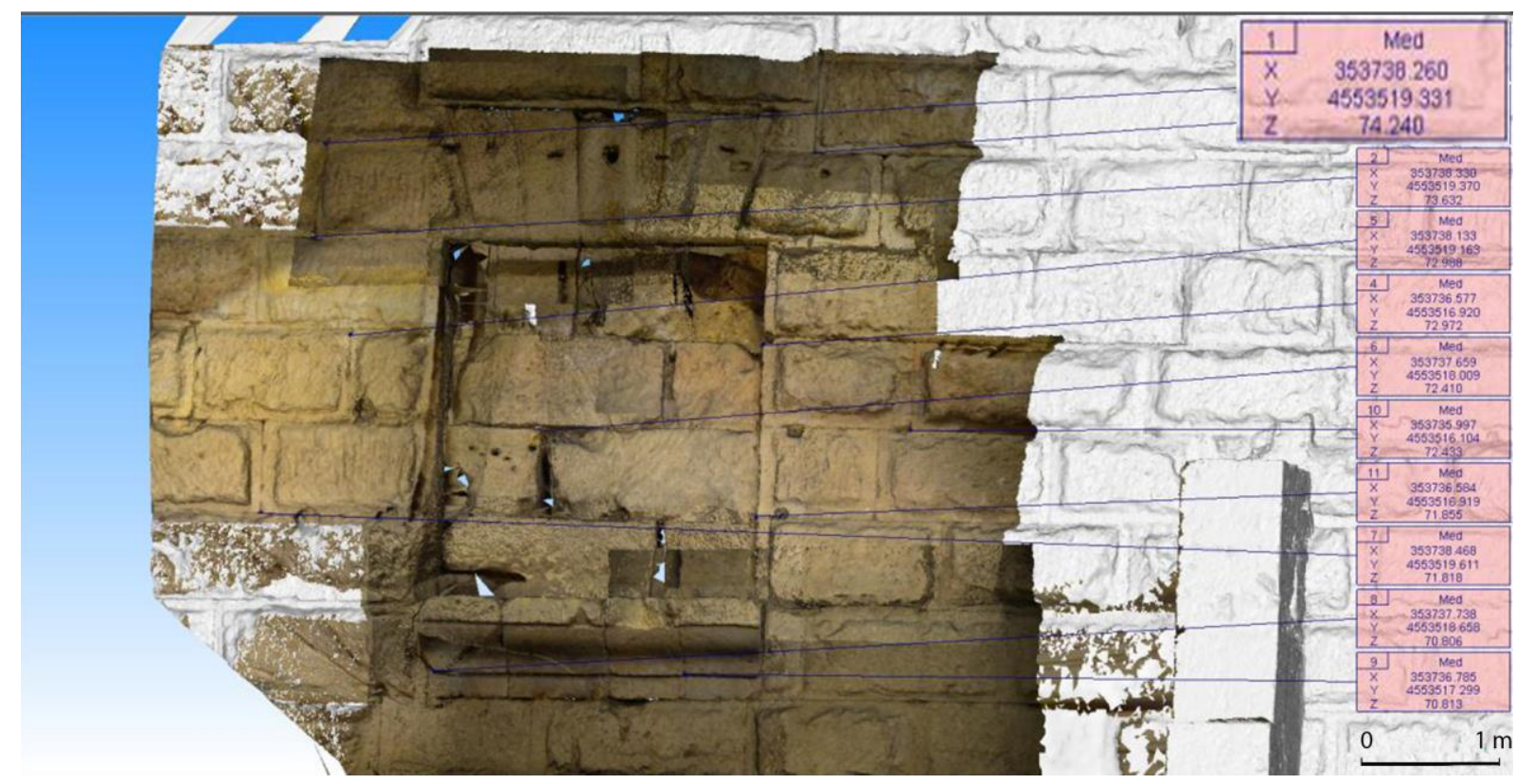

Fig. 4 Texturized model of the Roman window, and detail of a control points.

Objects with a horizontal flight strip perpendicular to the wall were photographed, with a minimum horizontal overlap of $60 \%$ and a minimum vertical overlap of $40 \%$. Correct stereoscopy between photographs had to be ensured to obtain an accurate model. All photographs were taken with the same camera using an $18 \mathrm{~mm}$ focal length, whose calibration parameters were known. 
To ensure optimal results in the calculation of orientation, a ratio of 1:3 and 1:5 was used for the location of the shot and the distance to the object. The software used in this case was Image Master of Topcon.

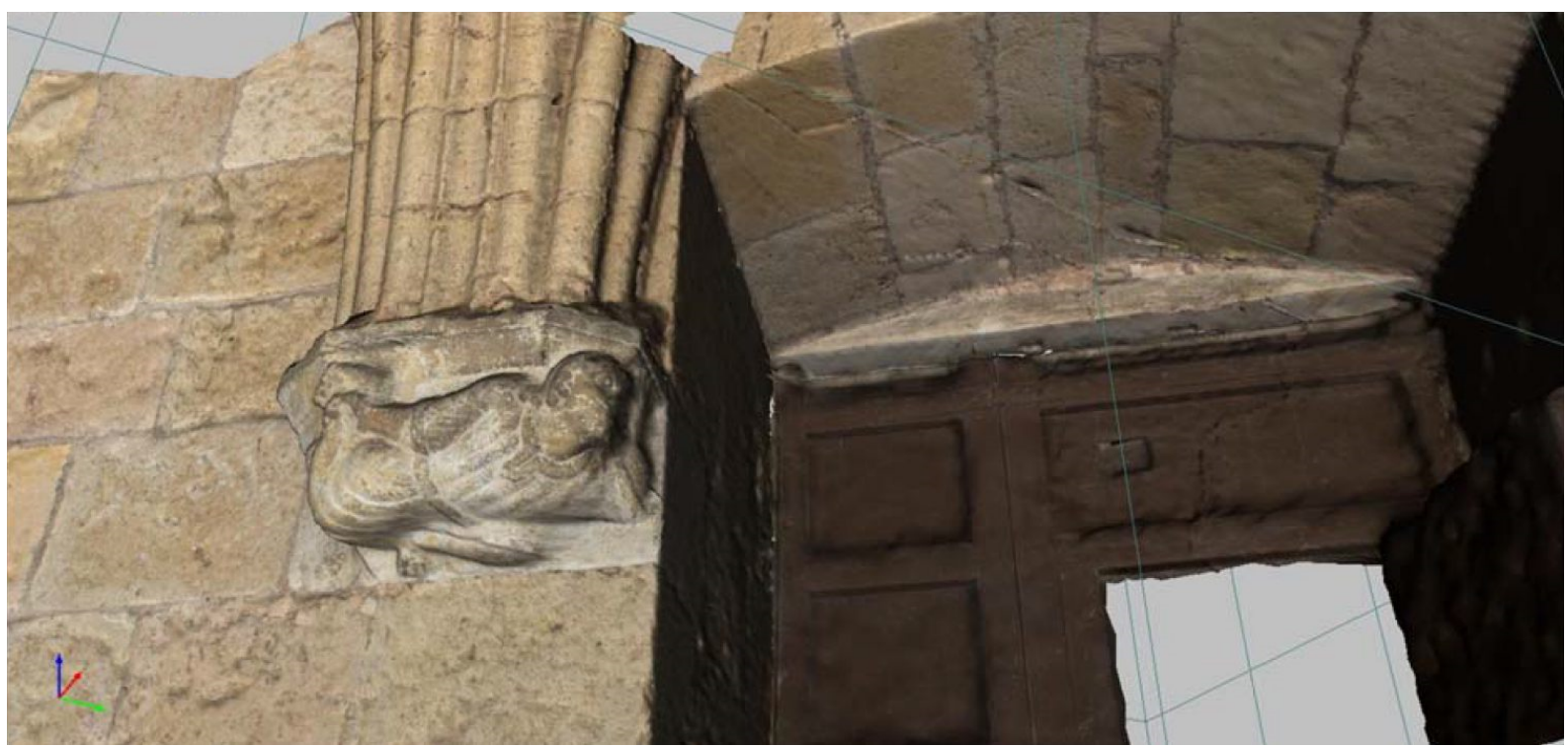

Fig. 5 The complete capital built by photogrammetric survey.

A previous relative orientation was performed to generate the $3 \mathrm{D}$ model. Stereoscopic pairs were processed separately, and the models were subsequently joined from a selection of the pairs. Then, the model was georeferenced with reference topographic points and an error of 2 millimetres.

\subsection{Assessment of the results}

Once the 3D model of the cloister had been obtained, it was processed to obtain the geometrical information needed for the structural analysis.

Initially, orthoimages were created, which provided information about the object from the previously created model.

An initial chronological assessment was performed that was based only on the built evidence and did not take into account historical data. It was used to graphically identify and subsequently isolate structural elements of the wall that were not part of the original construction. These elements were the walled areas of the three windows, the opening of the gateway to the wall from the Cathedral's cloister, and the structural arches located in the southern part of the wall. From these orthoimages, plans of the Roman wall were generated that represented their current state, a chronological map, and the original state (Figure 6). 


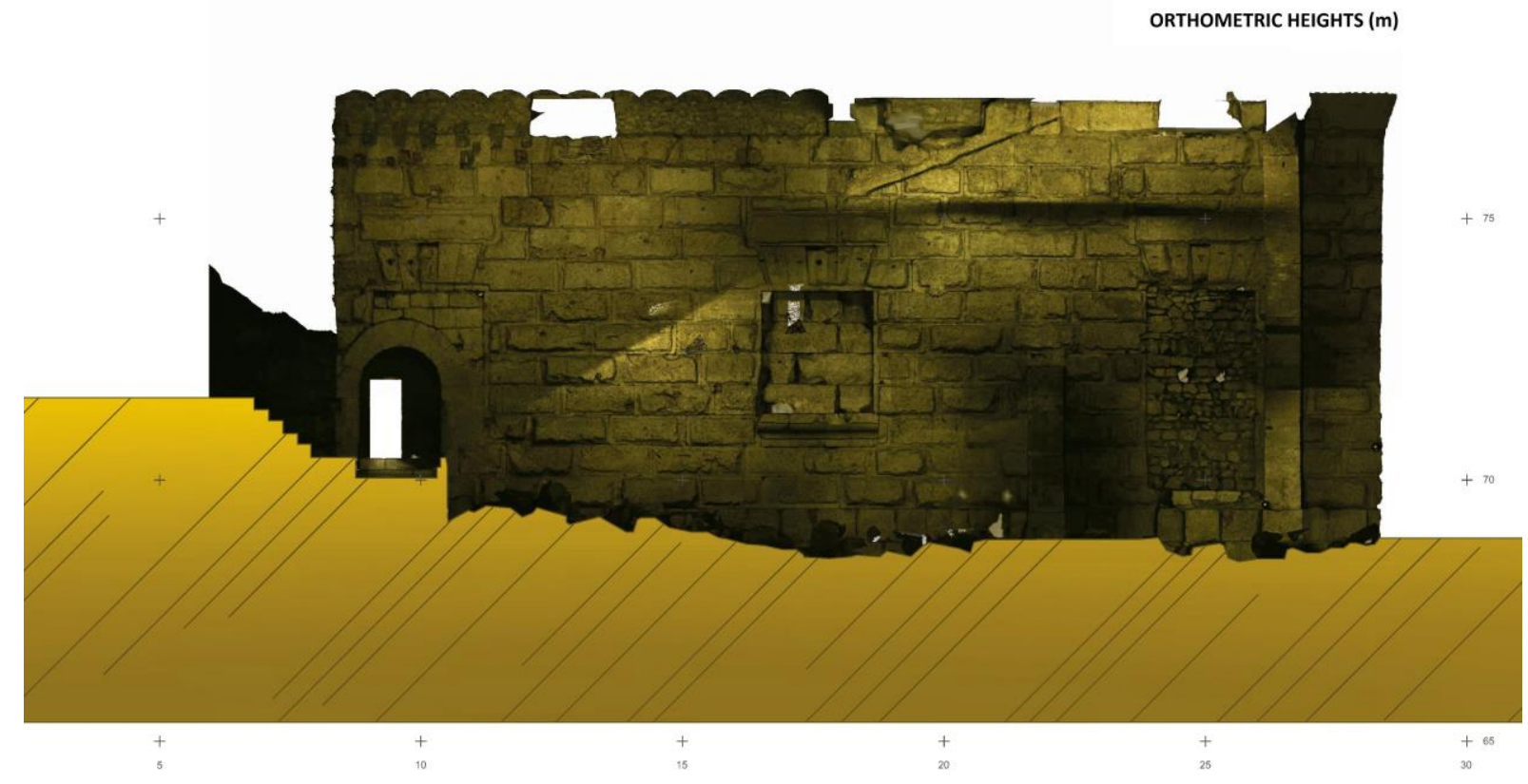

Fig. 6 Orthoimage of the current state of the Roman wall and the reference plane.

In addition, plans and elevations of the Roman wall were generated from the 3D model. Then, sections of the wall were put in the context of the original surroundings, to assess certain characteristics relative to the space adjacent to the wall itself (thickness).

Figure 7 shows the result of a frontal view, which clearly shows the bolstered face of the Roman ashlars of the wall. The hypsometric tins are defined by vertical sections of the model, parallel to the wall to show the collapse of the wall. It can be seen that it remains practically vertical.

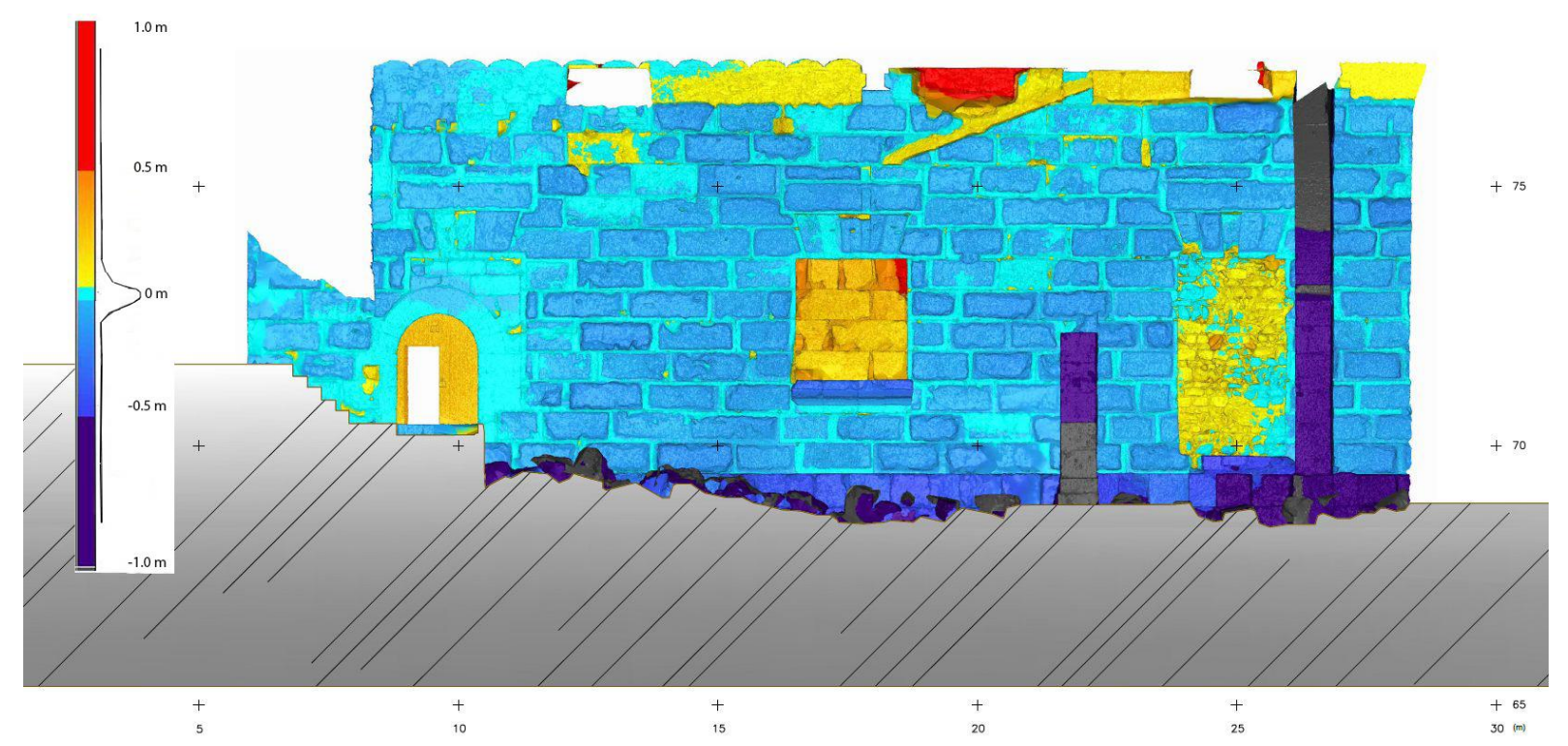

Fig. 7 Hypsometric tins of the Roman wall to show its collapse.

In addition, vertical sections were generated perpendicular to the wall at every metre, together with three more sections located in the centre of every original window of the wall. Moreover, three more vertical sections were created considering the context of the wall: one through the keystones of the vaults, another through the arches between the vaults of the gallery, and the last one through the 
middle of the gateway of the Roman wall. Horizontal sections were made at three different heights: bottom, medium and top. These sections revealed a certain leaning in the inner wall of the cloister, with values that reached between 7 and $9 \mathrm{~cm}$.

There are two reasons for inspecting and comparing meshes. First, to analyse the verticality of the wall, and second to compare meshes obtained by different methods at a particular point, in this case the window in the centre of the wall.

In order to analyse certain aspects of the structure of the Roman wall, it was compared with the reference plane that was previously defined by the orthoimage. It was found that around $23 \%$ of the assessed area was closer than $2.5 \mathrm{~cm}$ from the reference plane. The bolstered ashlars, which comprise $50 \%$ approximately of the analysed surface area, were not considered in the comparison. Protruding elements of the wall, such as arches, were also excluded from the analysis. Thus, the wall showed almost perfect verticality.

To examine the result of applying the radiation method with TLS and the photogrammetric model of the same element, the comparison was focused on one of three windows in the wall. The result of the analysis is shown in Figure 8. The two networks differed in the dark blue-coloured areas (which are the areas that were hidden in the photogrammetry).

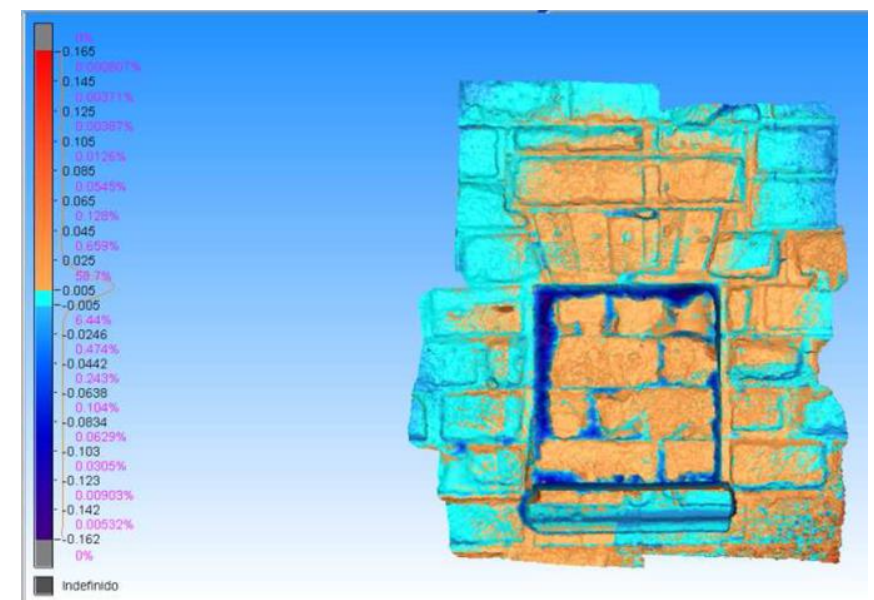

Fig. 8 Mesh comparison between the models obtained with laser scanner and photogrammetry. Measures in meters

Two examples are described below to highlight some of the applications of the three-dimensional models that were generated.

HTML files were generated directly with the 3D data that was acquired. The files can be used to navigate through the positions of the device in the field and can display any information obtained from each of them, with the possibility of taking real measures using the points of the cloud.

A video was created like a virtual guided tour, using three-dimensional models with textured pixel colour space to provide greater realism.

\section{Assessment of the equilibrium of one of the cloister's vaults}

\subsection{Case study}

Each of the cloister's vaults, except for the one at the corner, has the same architectural design despite small dimensional and geometric deviations that did not affect the results. The ribbed vault is 
quadripartite, and covers a slightly rectangular area of approximately $5 \times 6 \mathrm{~m}$. The mechanical behaviour will not be perfectly symmetrical, but it will be in the buttress system.

The vault rests on the former arches on the short side, while on the long side there are two different supports. One is the enclosing cloister wall, with an approximate average thickness of $135 \mathrm{~cm}$. This wall is composed of a medieval wall on the side of the cloister, and an ancient Roman wall on the other side. On the opposite side is a stretch of wall resting on three small arches with double circular columns and a small rectangular buttress that supports the thrusts of the vaults.

The balance in the former arch and the supporting system was analysed (Figure 9). The assessment took into account that the weight of the vault is transmitted through the former arch to the supports. As the vaults are symmetrical to the arc, the thrust of the two of them will be combined in the buttress, which reduces the problem to a two-dimensional issue.
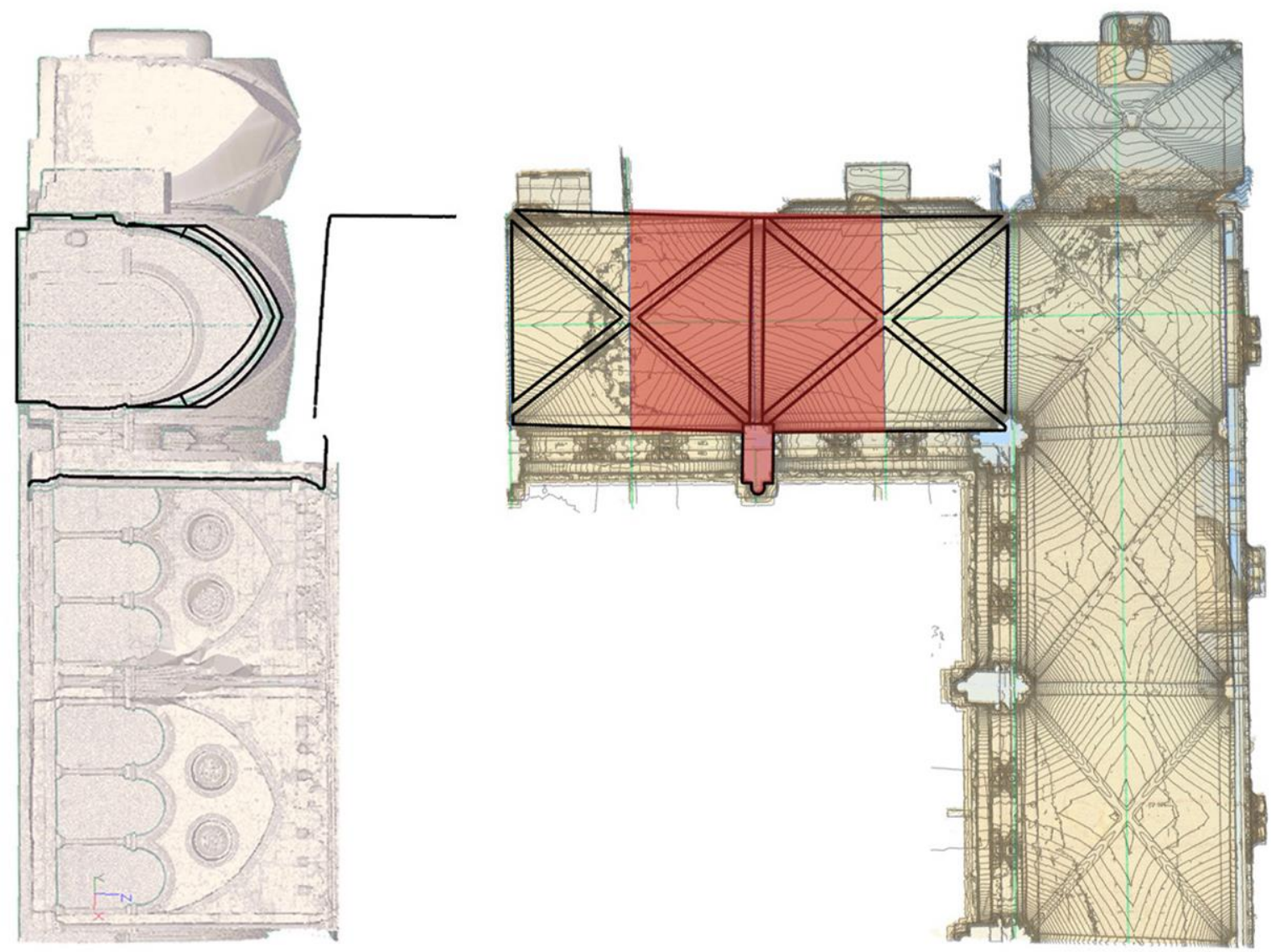

Fig. 9 Area of study highlight with a bold line.

According to the aim of the assessment, and the method used, we only needed to know the geometry and weight of the construction elements. Thus, usual values were used to define the mechanical properties of the materials, which were based on other analyses and normative of reference [30] [31]. Limit analysis through thrust lines was performed according to the geometry and weight of construction elements, and the results obtained are not very sensitive to small variations of values. The exterior surface of the vault was considered solid up to $1 / 2$ of its height, with a lightweight filling covered with ceramic tiles. Thus, we considered a stone with a specific weight of $24 \mathrm{kN} / \mathrm{m}^{3}$ and a filling of medium / high weight of $18 \mathrm{kN} / \mathrm{m}^{3}$. The geometric properties were defined by the laser 
scanner survey. Cross sections were laid out from the 3D model, obtaining the geometry of construction elements on 2D.

\subsection{Results of the limit analysis}

Limit analysis was used to calculate possible charge states according to a combination of hypotheses. The assessment of the structure involved calculating a range of possible solutions. Given the good condition of the structure, two main hypotheses were considered: minimum and maximum thrusts, together with different load conditions (Figure 10).

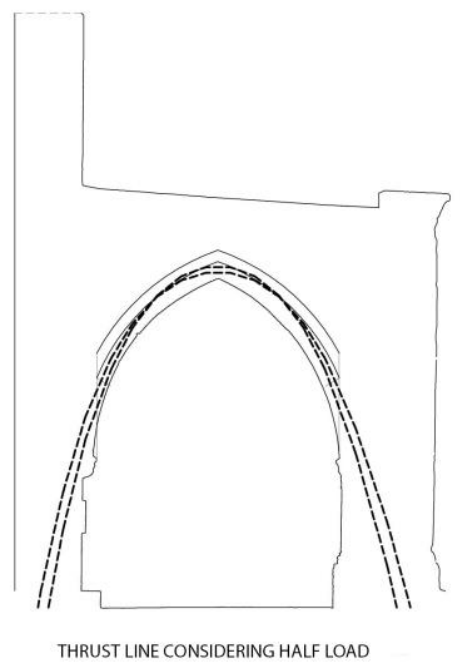

Fig. 10 Results of the limit analysis.

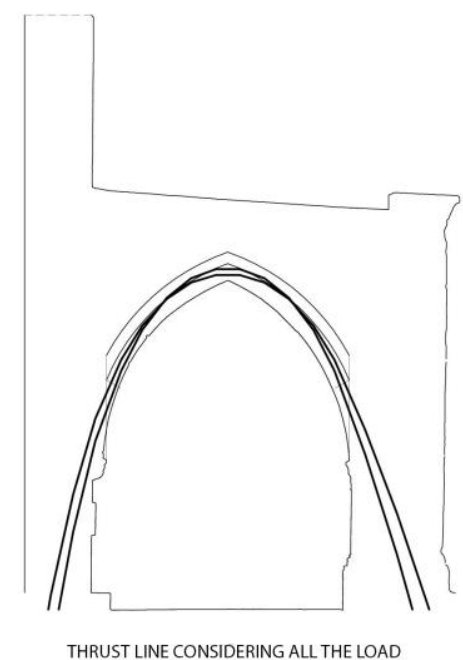

THRUST LINE CONSIDERING ALL THE LOAD

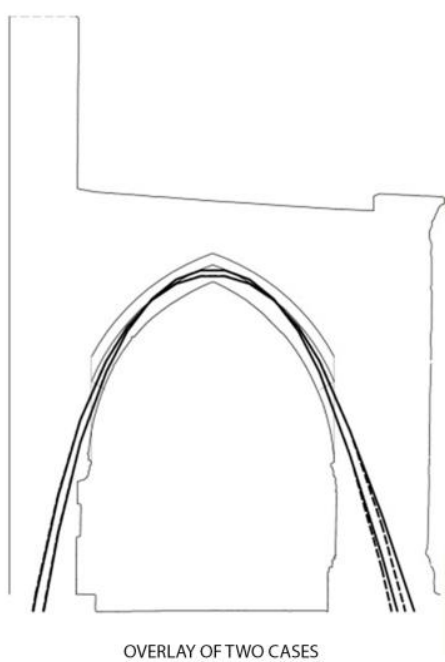

For the minimum thrust hypothesis, the resulting line of pressure was slightly outside of the arc section in the first third of its height. This hypothesis involved the work of the masonry webbing thickness, since otherwise it would appear as a joint in the arch. Regarding the abutment system, the thrust line was contained in the middle third in the base of the column, even without considering its overall weight, so that the structure could be considered perfectly balanced. As for the wall, the resulting line was also in the middle third. In this case, we had to consider a total width of $1.5 \mathrm{~m}$ (which was less than the vault span), since otherwise it was not possible to find a valid hypothesis combination.

In the maximum thrust hypothesis, the pressure line was contained in the thickness of the arch, so the thickness of the masonry webbing of the vault was not required to find a valid solution. Regarding the supports, the resulting line on the column was slightly outside the central third. The solution can be considered stable anyway, but tensiles could appear in the base. The resulting line of thrust in the wall was still in the masonry, but fell outside the middle third in the base. The wall section was considered lower than the span of the vault, so it was a worst case scenario and the wall could also be considered perfectly stable.

In order to verify the sensitivity of the model, the impact of reducing the load of the vault to the middle was checked. Despite the resultant thrusts are lower, the effect over the supporting system was uneven (Table 2). The result in the column was slightly better, though the change was not qualitatively significant. On the side of the wall, the same width as the column could be considered, so the solution was even more stable. 
Table 2. Weights and thrusts (minimum and maximum hypothesis) of the vault over the supports.

\begin{tabular}{|lccc|}
\hline & Weight $(\mathrm{kN})$ & Thrust (min.) $(\mathrm{kN})$ & Thrust (max.) (kN) \\
\hline Half Load & 254,6 & 93,5 & 112,0 \\
Complete Load & 503,5 & 185,0 & 221,3 \\
\hline
\end{tabular}

Additionally, the process of calculating volumes and gravity loads also shows the impact of each element on the overall structure. Naturally, most of the built volume, and consequently the loads, corresponded to the filling located on the extrados of the vault (Table 3).

Table 3. Volumes and weights of the vault construction elements.

\begin{tabular}{|lcccc|}
\hline & Volume $\left(\mathrm{m}^{3}\right)$ & Volume (\%) & Weight (kN) & Weight (\%) \\
\hline Arch & 0.3 & $1 \%$ & 6.7 & $1 \%$ \\
Vault & 3.8 & $14 \%$ & 91.5 & $18 \%$ \\
Filling & 22.5 & $85 \%$ & 405 & $81 \%$ \\
Total & 26.6 & $100 \%$ & 503,5 & $100 \%$ \\
\hline
\end{tabular}

\section{Discussion}

The laser scanning and photogrammetric survey revealed valuable information about the displacements suffered by the structure. The assessment of the vaulted ceiling showed geometrical discrepancies between elements that are theoretically equal. Main dimensions of the vaults are basically the same, but the surfaces show irregularities between vaults, and also between the different sides of the symmetry axe of the same vault. Movements on the supports could cause these geometrical variations, by errors during the execution or by a combination of both possibilities.

The 3D model obtained by massive data capture systems allows us to have the necessary sections in order to analyse exhaustively without having to measure new points or sections visiting the building again. This is of great importance when the objective of study is a cultural heritage building, with a huge number of visits by the tourist.

About the supporting system, the assessment of the verticality revealed that the Roman wall is almost perfectly vertical, despite the different and changing overloads that have been added through centuries. This composed wall is very thick, and it was built with medium/large sized stone ashlars, which results on a very monolithic construction. Moreover, the structure of the floor on the other side braces it, which makes it more stable.

On the other side, the inner wall of the gallery has leaned. This is very perforated, is not fastened with any perpendicular element, and is composed by different small parts in balance. All this characteristics makes the overall structure less rigid than the opposite wall. 
About the limit analysis, the thrust lines found are perfectly contained in the section of the masonry structure. So according to the lower bound theorem, in general terms the construction can be considered as stable. A more accurate interpretation of the analysis highlights that the thrust line is closer to the edge of the column of the inner wall at the base, which may result in rotation of the base. This result together with the different rigidities of both sides, explain the leaning of that part of the structure.

The data capture with laser scanning take half a day in field, the same that the photogrammetric survey, but it implies a week of office work to give colour to the points from the images, to edit the point cloud, to filter the blunders and noise, obtained and correct the triangle mesh. This part takes some days since the ornamentation of the cloister have several holes that provoke the generation of false triangles. These times are a general rule, one day of fieldwork implies one week of processing.

\section{Conclusions}

Remains of buildings from different eras are often found in cathedral enclosures. The cloister of Tarragona Cathedral has unique structural characteristics, due to the existence of a large Roman wall that borders the site to the northwest. Massive data capture techniques provide a lot of geometric information and are a powerful tool in the analysis and conservation of heritage buildings. In the case explained here, the topographic survey enabled us to assess the preservation and equilibrium conditions of the vaulted structure and its supports, including the Roman wall. A first analysis of the verticality of the walls revealed that the Roman/medieval wall has hardly suffered displacements, while the opposite side has leaned in some places, which indicates the existence of certain stability issues.

An analytical assessment of the structure by graphic techniques enabled us to evaluate its equilibrium. On the side of the wall, it was found that the mechanical behaviour of the joint between the initial Roman wall and the medieval wall is essential to ensure the stability of the whole structure, since otherwise the buttressing would be insufficient. On the opposite side, the mechanical behaviour of the structure is different, and is more sensitive to load variations. Both sides have very different rigidities, which may have caused the leaning of the inner wall. Moreover, it should be noted that conclusions are focused on a little part of the overall structure. Further research should assess the complete masonry construction to understand fully the mechanical behaviour and the equilibrium conditions of the Gothic cloister and its Roman wall.

\section{References}

[1] VENICE. 1964. International Charter for the Conservation and Restoration of Monuments and Sites (the Venice charter 1964). Website http://www.icomos.org/charters/venice_e.pdf (Accessed, September 15, 2016).

[2] ICOMOS. 1966. Principios para la Creación de Archivos Documentales de Monumentos, Conjuntos Arquitectónicos y Sitios Históricos y Artísticos (1966). Website http://www.esicomos.org/nueva_carpeta/info_DOC_ARCHIVOS.htm (Accessed, September 15, 2016). 
[3] ISCARSAH. 2003. Principios para el análisis, conservación y restauración de las estructuras del patrimonio arquitectónico (2003). Website https://iscarsah.org/documents/ (Accessed, September 15, 2016).

[4] Fassi, F., Achille, C., Fregonese, L. 2011. Surveying and modelling the main spire of Milan Cathedral using multiple data sources. Photogrammetric Records, 26 (136), 462-487.

[5] Martínez, S., Ortiz, J., Gil, M. L., Rego, M. T. 2013. Recording Complex Structures Using Close Range Photogrammetry: The Cathedral of Santiago de Compostela. Photogrammetric Records, 28 (144), 375-395.

[6] Pesci, A., Teza, G., Bonali, E., Casula, G., Boschi, E. 2013. A laser scanning-based method for fast estimation of seismic-induced building deformations. ISPRS Journal of Photogrammetry and Remote Sensing, 79, 185-198.

[7] Pesci, A., Casula, G., Boschi, E. 2011. Laser scanning the Garisenda and Asinelli towers in Bologna (Italy): Detailed deformation patterns of two ancient leaning buildings. Journal of Cultural Heritage, 12 (2), 117-127.

[8] Bonali, E., Pesci, A. Casula, G. Boschi, E. 2014. Deformation of Ancient Buildings inferred by Terrestrial Laser Scanning methodology: the Cantalovo church case study (Northern Italy). Archaeometry, 56 (4), 703-716.

[9] Alonso, A., Martinez, A., Llopis, V., Moreno, J. 2012. Structural behaviour analysis of the dome of the Cathedral of Valencia. Structural Analysis of Historical Constructions, SACH. Wroclaw, Poland.

[10] Block, P., De Jong, M., Ochsendorf, J. 2006. As Hangs the Flexible Line: equilibrium of Masonry Arches. Nexus Network Journal, 8(2), 13-24.

[11] Heyman, J. 1997. The stone skeleton: structural engineering of masonry architecture. Cambridge University Press.

[12] Huerta, S. 2004. Arcos, bóvedas y cúpulas. Geometría y equilibrio en el cálculo tradicional de estructuras de fábrica. Instituto Juan de Herrera, 314-332.

[13] Ochsendorf, J. 2002. Collapse of Masonry Structures. PhD thesis. University of Cambridge.

[14] Roca, P., Cervera, M., Gariup, G., Pelà, L. 2010. Structural Analysis of Masonry Historical Constructions. Classical and Advanced Approaches. Archives of Computational Methods in Engineering, 17 (3), 299-325.

[15] Lluis, J., Costa-Jover, A., Fortuny-Anguera, G. 2015. Elementos auxiliares de construcción en la arquitectura gótica. El pilar «major» de la catedral de Tortosa. Informes dela construcción, 67 (537).

[16] Schueremans, L., Van Genechten, B. 2009. The use of 3D-laser scanning in assessing the safety of masonry vaults. A case study on the church of Saint-Jacobs. Optics and Lasers in Engineering, 47 (3-4), 329-335. 
[17] Lubowiecka, I., Armesto, J., Arias, P., Lorenzo, H. 2009. Historic bridge modelling using laser scanning, ground penetrating radar and finite element methods in the context of structural dynamics. Engineering Structures, 31(11), 2667-2676.

[18] Morer, P., de Arteaga, I., Armesto, J., Arias, P. 2011. Comparative structural analyses of masonry bridges: An application to the Cernadela Bridge. Journal of Cultural Heritage, 12(3), 300-309.

[19] Riveiro, B., Solla, M., de Arteaga, I., Arias, P., Morer, P. 2013. A novel approach to evaluate masonry arch stability on the basis of limit analysis theory and non-destructive geometric characterization. Automation in Construction, 31, 140-148.

[20] Hauschild, Th. 1974. Römische Konstruktionen auf del oberon Stadtterrassen des antiken Tarrac. Archivo Española de Arqueología, 47-48, 3-44.

[21] Barral, X. 1994. La Catedral de Tarragona. Pòrtic.

[22] Macias, J. M., Muñóz, A. 2013. Tarraco Christiana Ciuitas. A. M. Melgar (Ed.). Institut Català d'Arqueologia Clàssica.

[23] Liaño, E. 2007. La Catedral de Tarragona i les esglesies de Sant Pau i Santa Tecla. El Tarragones, March Editor, 94-123.

[24] Ramos, M. L. 2005. Catedral de Tarragona. Geoestel. Riveiro, B., Morer, P., Arias, P., de Arteaga, I. 2011. Terrestrial laser scanning and limit analysis of masonry arch bridges. Construction and Building Materials, 25(4), 1726-1735.

[25] Macias, J. M., Muñoz, A., Peña, A., Ramon, M., Teixell, I. 2012: Praesidium, Templum et Ecclesia. Les intervencions arqueològiques a la Catedral de Tarragona (2010-2011). Memòria d'una exposició temporal.

[26] Macias, J., Fiz, I., Piñol, L., Miró, M., Guitart, J. 2007: Planimetria arqueològica de Tarraco. Tarragona: ICAC.

[27] Salonia, P., Bellucci, V., Scolastico, S., Marcolongo, M., Leti Messina, T. 2007. 3D survey technologies for reconstruction, analysis and diagnosis in the conservation process of cultural heritage. In Proceedings of CIPA.

[28] De Matías, J., Berenguer, F., Cortés, J. P., De Sanjosé, J. J. Atkinson, A. 2013. Laser Scanning for the geometric study of the Alcántara Bridge and Coria Cathedral. ISPRS-International Archives of the Photogrammetry, Remote Sensing and Spatial Information Sciences, 1(1), 51-56.

[29] Castagnetti, C., Bertacchini, E., Capra, A., Dubbini, M. 2012. Terrestrial Laser Scanning for Preserving Cultural Heritage: Analysis of Geometric Anomalies for Ancient Structures. In Proceedings of the FIG Working Week.

[30] Costa-Jover, A., Lluis, J., Coll-Pla, S. 2017. Limit Analysis and the Study of Building Stages in Masonry Structures. Experiences with the Gothic Apse of Tortosa Cathedral (1345-1441). 2017. International Journal of Architectural Heritage, 11 (4), 475-489. doi: http://dx.doi.org/10.1080/15583058.2016.1246625. 
[31] Código Técnico de la Edificación. 2009. Documento Básico Seguridad Estructural. Acciones en la Edificación. Table C1 [in Spanish] 